\title{
BMJ Open Temporal trends of physician geographical distribution and high and intermediate physician density areas and factors related to physicians' movement to low physician density areas in Japan: a longitudinal study (1996-2016)
}

\author{
Masatoshi Ishikawa (D) 1,2
}

To cite: Ishikawa M. Temporal trends of physician geographical distribution and high and intermediate physician density areas and factors related to physicians' movement to low physician density areas in Japan: a longitudinal study (1996-2016). BMJ Open 2020;10:e041187. doi:10.1136/ bmjopen-2020-041187

- Prepublication history for this paper is available online To view these files, please visit the journal online (http://dx.doi. org/10.1136/bmjopen-2020041187).

Received 02 June 2020 Revised 26 0ctober 2020 Accepted 07 November 2020

Check for updates

(c) Author(s) (or their employer(s)) 2020. Re-use permitted under CC BY-NC. No commercial re-use. See rights and permissions. Published by BMJ.

${ }^{1}$ Takemi Program in International Health, Harvard T.H. Chan School of Public Health, Boston, Massachusetts, USA

${ }^{2}$ Faculty of Medicine, University of Tsukuba, Tsukuba, Japan

Correspondence to Dr Masatoshi Ishikawa; masa.ishikawa1221@gmail.com

\section{ABSTRACT}

Objectives A major issue in Japan's health policy is the geographical maldistribution of physicians. This study aimed to analyse temporal trends in the geographical distribution of physicians and analyse physicians in high and intermediate physician density areas and factors related to their movement to low physician density areas in Japan.

Design A longitudinal study.

Setting All physicians in 344 secondary medical districts. Participants I analysed data from the biennial national census, conducted by the Ministry of Health, Labour and Welfare between 1996 and 2016 and and divided it into two cohorts of 10 years each: 1996-2006 and 2006-2016.

Primary and secondary outcome measures I estimated the temporal trends in the number and percentages of physicians, and used logistic regression to analyse physicians in high and intermediate physician density areas and the factors related to their movement to low physician density areas.

Results The overall number of Japanese doctors increased by 31\% between 1996 and 2016. The number of physicians per population in the physician high-density areas increased by $29 \%$, while those in low-density areas increased by $32 \%$, suggesting that the gap between areas marginally decreased. The multivariable logistic regression analyses revealed that academic hospital experience had the highest $\mathrm{OR}$ for predicting physician movement to low physician density areas after 10 years, both in the 1996 and 2006 cohorts. Other factors that positively correlated with physician movement were being male, being younger than 40 years, being qualified after the age of 30 , urban area, intermediate physician density area and practice in a non-academic hospital.

Conclusions As less-experienced physicians demonstrate high mobility among geographic categories, and retention rates are low in low physician density areas, especially for less-experienced physicians, a new system that considers these factors would create opportunities for younger physicians to work in low-density areas.
Strengths and limitations of this study

- This study longitudinally examines the geographic distribution of physicians in Japan, focusing on physician density by secondary medical districts using individual physician data with permission from the national government.

- To improve the uneven distribution of physicians, especially for less-experienced physicians, a new system that considers these factors would create opportunities for younger physicians to work in these low-density areas.

- This study only focused on correlations and was unable to determine causality. Future studies could use interviews and questionnaires to facilitate more comprehensive research for physician migration.

- The observation period is 20 years. The effects of various environmental changes, such as the global economic crisis, policy changes for physician maldistribution, and population ageing, were not considered.

\section{INTRODUCTION}

The uneven geographical distribution of physicians is a critical issue for Japan's health policy that is perhaps related to the Japanese government's lack of restrictions on physicians' work location choices. ${ }^{1}$ As a result, although the number of physicians is increasing, there is little improvement in geographic imbalance. ${ }^{23}$ Historically, a Japanese university's medical schools were responsible for pooling and dispatching doctors to urban and rural hospitals according to their specialties. Residency training was not previously mandatory, and medical schools would send graduates directly to practice. However, a new residency training programme for physicians was nationally launched in 2004 
that requires young doctors to choose a clinical training hospital outside of their university in the first 2 years after graduation. ${ }^{4}$ This programme has weakened the university hospital system, as it has forced new physicians to choose specialisations, in hospitals where they can find a position, and thereby exacerbated geographic imbalances. ${ }^{5-8}$

To address this geographic imbalance, several policies have been established..$^{9}$ First, the number of medical students rose from 7625 in 2007 to 9420 in 2017, because of increased medical school capacity. Second, a system for selecting students was developed with the primary objective of recruiting physicians, mainly in rural areas. This system included 1674 medical students in 2017 , $18 \%$ of the capacity of medical schools. Many medical students earn prefectural scholarships and are excluded from reimbursements if they serve at a designated medical institution for a fixed time period. Despite these policies, maldistribution persists. ${ }^{10}$ Further, a 2018 revision in the Medical Care Act encourages prefectures to take effective measures to secure the necessary number of physicians according to specialisations to remedy geographical maldistribution. Currently, a policy is being drafted that acts as a countermeasure for maldistribution. It requires hospital directors to procure work experience in low physician density areas for a certain period and thus incentivises physicians. ${ }^{11}$

Several previous studies have highlighted the relationship between geographic movement and physician features such as gender, age and specialisation. ${ }^{12-14}$ For instance, a 2002 study found that doctors who had practiced rural care in 1980 were more likely to stay in rural care. This pattern was more pronounced among men, older doctors and/or primary care professionals. ${ }^{12}$ As these data come from the physician population in 1980, it is difficult to apply it to recent developments, such as the rise in female physicians and the influence of new residency training systems. Many US studies have investigated male and female physicians, ${ }^{13}$ as well as white, black and foreign graduates of medicine, ${ }^{14}$ and found that they often move locations. For Japan, however, there have not been any studies that explore the transition from lower to higher physician density areas. Because of this gap in the literature, the purpose of the present study was to identify the factors associated with physician movement between various physician density areas in Japan. The findings can inform efforts to prevent uneven distribution of doctors, based on differences in physician density.

\section{METHODS}

I used individual physician data from the Survey of Doctors, Dentists, and Pharmacists, a nationwide census survey conducted every 2 years by the Japanese Ministry of Health, Labour and Welfare (MHLW), collected over two decades (1996 through 2016). In Japan, all physicians are expected to report their status every 2 years under the Medical Practitioners' Act. As such, the response rate was around $90 \%{ }^{15}$
I analysed physician demographic data from 1996, 2006 and 2016, particularly focusing on registration numbers, gender, age, experience, type of workplace (municipal and institutional) and medical practice. I developed two cohort datasets (1996-2006 and 2006-2016) using the physician registration numbers and analysed geographical movement patterns. When creating the cohort dataset, I analysed the physicians who responded in both years. Additionally, in the original data obtained from the Ministry of Health, Labour and Welfare, there were no incomplete or missing data.

In terms of geography, I categorised the 344 secondary medical areas (SMAs) in Japan in 2016 into three groups based on the combinations of population size and density: (1) urban, (2) intermediate and (3) rural. In Japan, as in the US Office of Management and Budget, the definition of rural is not always consistent. ${ }^{16}$ The categorisations used were the MHLW classification position statements regarding the demand for physicians ${ }^{17}$ Based on the classification used by MHLW, the first group (urban) consists of areas with a population of at least 1 million or a population density of at least 2000 people $/ \mathrm{km}^{2}$. The second group (intermediate) consists of areas with a population of at least 100000 or a population density of at least 200 people $/ \mathrm{km}^{2}$. The third group (rural) consists of areas that do not belong to the first or second groups. The municipality borders that were altered because of mergers were adjusted based on the borders used in 2016. Physicians who were in the same SMA category during the study period were considered to be retained there.

I determined the number of physicians in each SMA group per 100000 population by using total number of physicians and total population data. To account for the disparity in physician data years (1996, 2006 and 2016) and population data years $(1995,2005$ and 2015), I applied the physician data to the previous year of population data: physician 1996 to population 1995, physician 2006 to population 2005 and physician 2016 to population 2015. Regarding the number of physicians per SMA in 1996, 2006 and 2016, the top 33.3\% were classified as areas with many physicians and the bottom $33.3 \%$ as those with fewer physicians, based on the MHLW physician density classifications in 1996, 2006 and $2016 .^{11}$

The physicians were classified into four categories, depending on the employment agency: clinics, university hospitals, other hospitals and other (eg, public health centres, industrial physicians and unemployed physicians). In Japan, clinics are defined as medical institutions with less than 20 inpatient beds, while hospitals have more than 20 inpatient beds. To determine the relationship between specialisations and clinic forms, I identified and labelled the doctors who registered with specialties in internal medicine, general surgery or paediatrics as primary care physicians. Physicians, general surgeons and paediatricians play a significant role in primary care, as there is a lack of recognised primary care skilled physicians comparable to US family medicine physicians in the Japanese healthcare system. ${ }^{18}$ 
I described the distribution of physicians by their density in 1996, 2006 and 2016, based on the physician density classification in 2016. Then, I illustrated the inflow and outflow of physicians by physician density classification during the two periods (1996-2006 and 2006-2016) based on the physician density classifications in 1996, 2006 and 2016. Next, regarding low physician density areas, for the data from 1996 to 2016, I calculated the retention rate every 2 years and analysed the trends.

Subsequently, regarding the two cohorts (1996-2006 and 2006-2016), I excluded physicians who were already in the low physician density area. I then analysed physicians in high and intermediate areas and the factors related to their movement to low physician density areas after 10 years, from 1996 and 2006, through a multivariable logistic regression analysis based on the physician density classifications in 1996, 2006 and 2016. Intermediate and high physician density areas were set at three different time points (1996, 2006 and 2016). Additional information on the number of SMAs that changed classification between those time periods was also described.

For all statistical analyses, I used STATA V.15.1 and considered $p$ values of less than 0.05 as significant.

\section{Patient and public involvement}

Patients or the public were not involved in the design, or conduct, or reporting, or dissemination plans of our research.

\section{RESULTS}

In the 1996, 2006 and 2016 physician surveys, data were available for 240 396, 277927 and 319474 physicians, respectively. Figure 1 shows the number of physicians per 100000 by region in 1996, 2006 and 2016. During this period, the overall number of doctors increased by $31 \%$ (from 191.4 to 251.4). Based on physician density criteria, the number of physicians per population in high physician density areas increased by $29 \%$ (from 250.6 to 323.9 ), while those in low physician density areas increased by $32 \%$ (from 112.8 to 149.0 ).
Table 1 displays all physicians' characteristics in 1996, 2006 and 2016. Between 1996 and 2016, the number of female physicians increased 2.1-fold and the proportion of female physicians increased from $13.4 \%$ to $21.1 \%$. Between 1996 and 2006, the number of physicians aged 40-54 increased by $39 \%$, while between 2006 and 2016, those aged 55-69 rose by $74 \%$. In terms of facilities, the number of doctors in university hospitals grew by 23\% between 2006 and 2016. Between 1996 and 2016, the number of primary care doctors remained nearly unchanged in terms of specialties, while the proportion of primary care physicians dropped from $46.4 \%$ to $35.2 \%$.

Table 2 describes physician relocation from high-density to low-density areas between 1996 and 2006 and between 2006 and 2016. The 1996-2006 data revealed that $82.8 \%$ of doctors operating in high physician density areas in 1996 remained in these areas. Migration from highdensity to low-density areas was low $(6.1 \%)$. In comparison, $68.0 \%$ of doctors in low physician density areas in 1996 also remained in these regions, while the rest relocated to high-density and intermediate-density areas. In the 2006-2016 data, 85.3\% working in high physician density areas remained in these regions in 2006. Once again, there was a low migration from high-density to lowdensity regions $(4.9 \%)$. By comparison, $70.2 \%$ of those working in low physician density areas in 2006 stayed in those regions, and the rest relocated to high-density and intermediate-density areas.

Table 3 presents our estimations of the annual retention rates. The proportion of physicians who stayed in low physician density regions between 2014 and 2016 was $83.1 \%$. This increase is indicative of general retention over the 1996-2016 period, which slightly increased from $80.5 \%$ to $83.1 \%$. However, physicians with less than 15 years of experience tend to have a lower retention rate, and many begin working in low physician density areas.

Table 4 first shows the logistic regression results that served to identify the variables in 1996 that predicted physicians being engaged in high and intermediate areas and the factors related to their movement to low physician

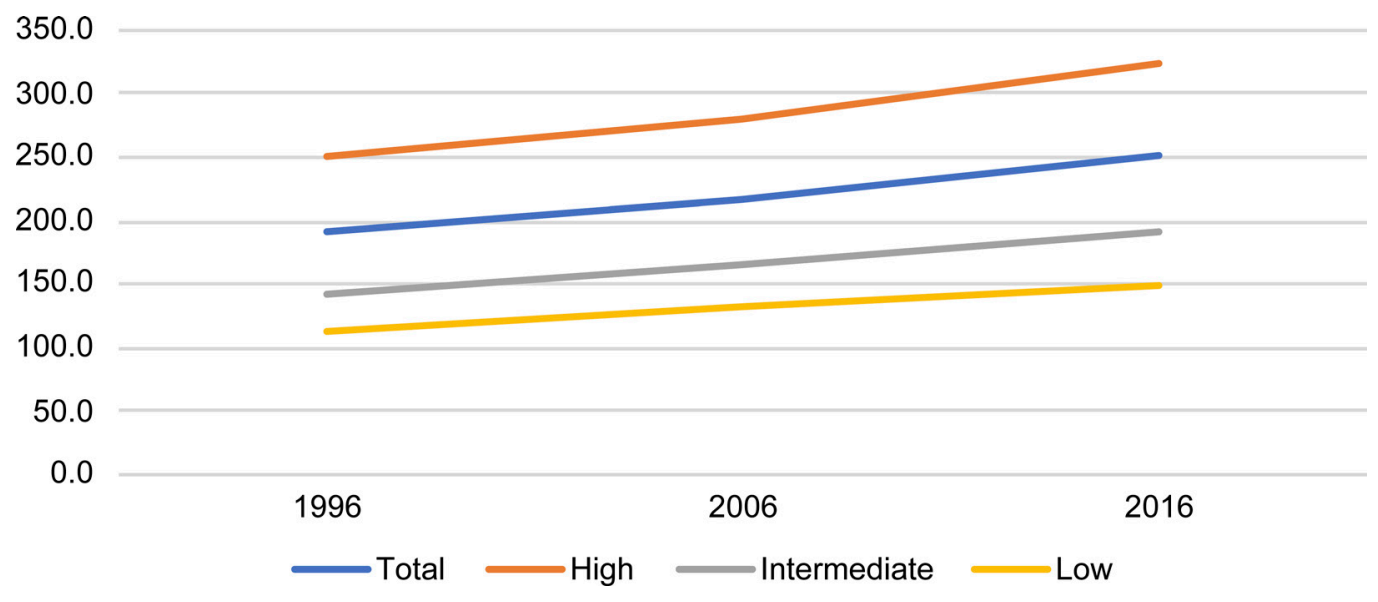

Figure 1 Distribution of physicians per 100000 residents by geographic area in 1996, 2006 and 2016 in Japan. 
今े

ஸे ळें ळे ळें

$\circ \circ$

$\circ \circ$

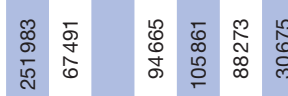

₹ै

$\dot{\mathrm{i}} \overline{\mathrm{N}}=$

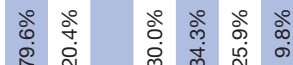

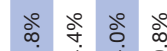

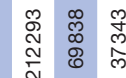

अ \&

离

商

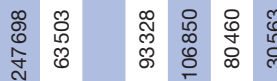

ले 虫

วัํํำ จำ

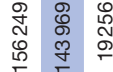

党

西

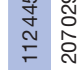

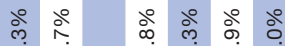

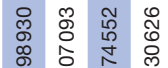

응

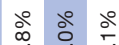

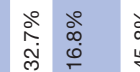

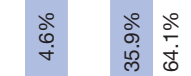

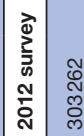

क्ष

के लें

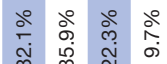

ते 仓ิ

용 눙 흥

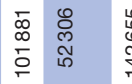

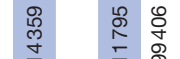

ปัญ

赵 용 ₹

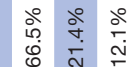

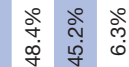

今े @े ڤे

ฌ̊

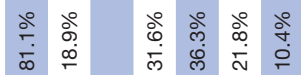

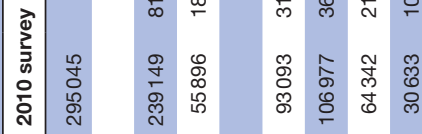

Sิ

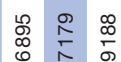

앙 $\begin{aligned} & 0 \\ & 0 \\ & 0\end{aligned}$

ஃั วัํำ

\ัे

วั่ ถั ํํำ

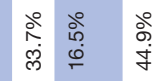

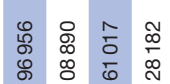

导 $\frac{10}{5}$

용

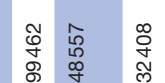

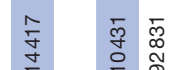

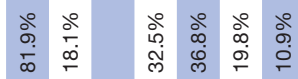

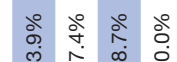

강

का

离

ס

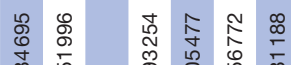

동ำ

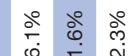

ํำ

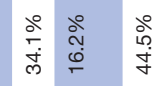

เे

วั จำ

○े ஃे ஃे

ஸे

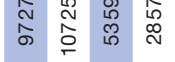

¿

ఫิ

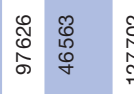

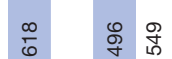

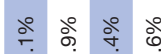

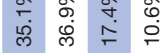

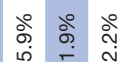

ஃั วั

六

ลे ஃั วั

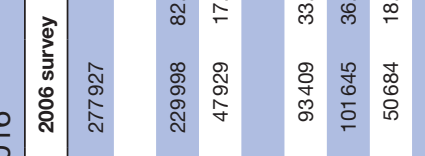

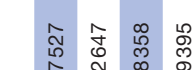

$$
\text { ठิ }
$$

造

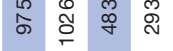

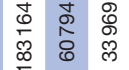

бo

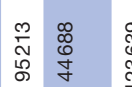

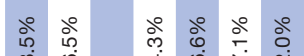

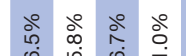

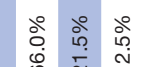

วัे ㅇํํ

守

ळ

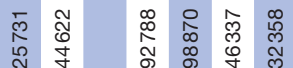

:

$\circ$

के बु

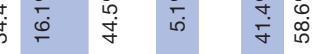

อำ ปั

守 高

为

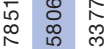

要

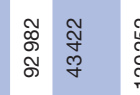

임

ले तู่

은

章

क ம்

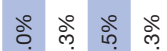

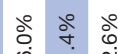

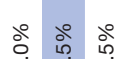

守

:

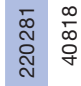

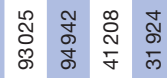

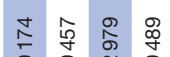

ڤั)

द

(1)

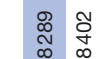

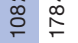

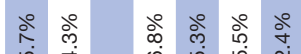

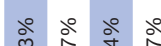

స్

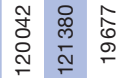

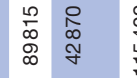

ลे

i̊

岗

लं ले

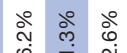

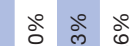

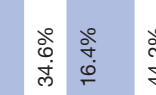

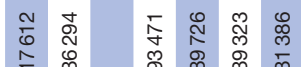

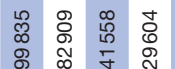

苛 ஜ

द व

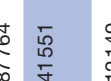

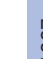

둗응

空

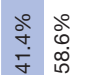

ஃั ๖े

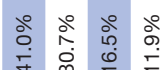

ㅇำ

必

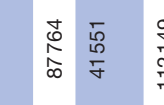

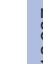

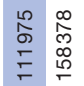

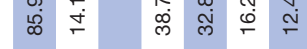

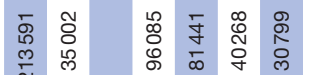

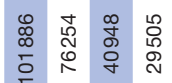

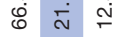

今े @ें

ฌे

๖े

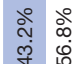

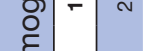

ஃั

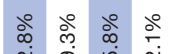

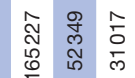

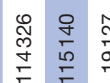

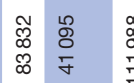

๖

号

ळ.

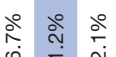

ㅇำ ㅇำ

ำ

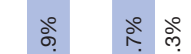


Table 2 Physician density and physician migration

\section{6-2006 cohort}

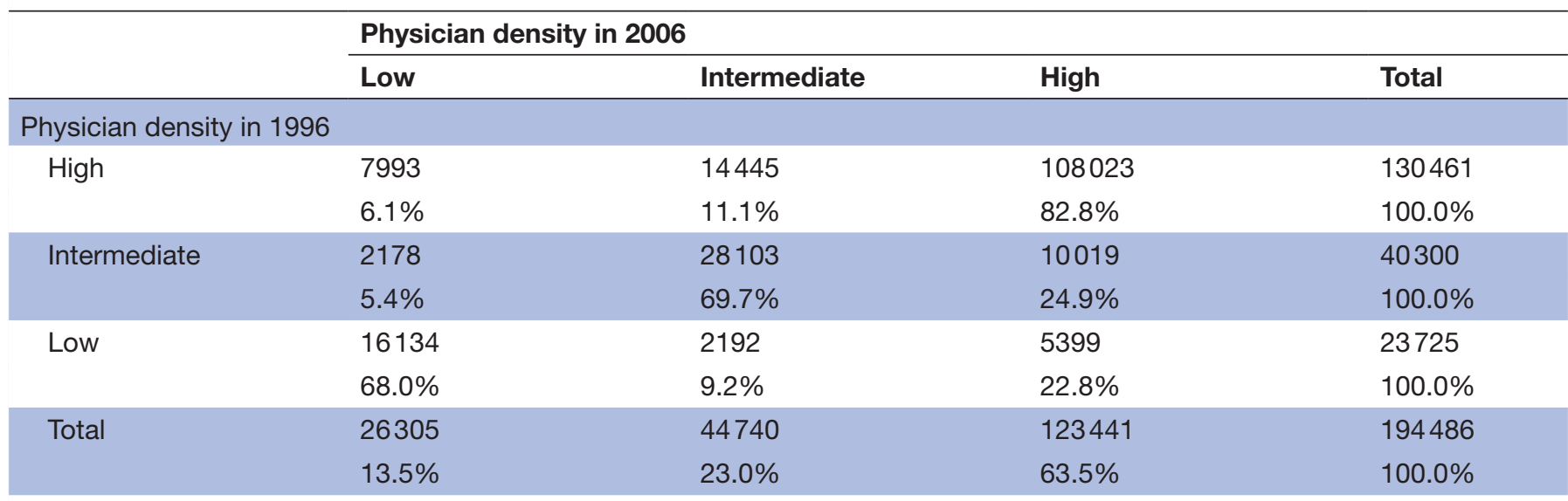

\section{6-2016 cohort}

\section{Physician density in 2016}

\begin{tabular}{lllll} 
Physician density in 2006 & & & & \\
High & 7364 & 14822 & 129067 & 151253 \\
& $4.9 \%$ & $9.8 \%$ & $85.3 \%$ & $100.0 \%$ \\
Intermediate & 2427 & 35212 & 11256 & 18895 \\
& $5.0 \%$ & $72.0 \%$ & $23.0 \%$ & 28155 \\
Low & 19751 & 2469 & 5935 & $100.0 \%$ \\
Total & $70.2 \%$ & $8.8 \%$ & $21.1 \%$ & 228303 \\
& 29542 & 52503 & 146258 & $100.0 \%$ \\
\hline
\end{tabular}

density areas in 2006. The following factors positively predicted their movement to low physician density areas: being men, hospital practice, under 40 years of age and qualified after the age of 30. However, rural and intermediate area practice in 1996 were negative predictors of low physician density area practice in 2006. Among the variables, practice in university hospitals was the strongest predictor, with an OR of 6.15 over the other variables. Table 4 also shows the analysis results that identify the variables in 2006 that predicted low physician density area practice in 2016. These variables were the same as those in the 1996-2006 cohort results. University hospital practice was again the strongest predictor, with an OR of 4.87 over the other variables.

There were 51 SMAs $(15 \%)$ whose classification changed during the period between 1996 and 2006 and $62(18 \%)$ between 2006 and 2016, as shown in table 5 .

\section{DISCUSSION}

This study revealed that the increases in physicians per population in high-density areas were less than the increases in low-density areas, suggesting that the physician geographical imbalance has improved based on percentage improvements over time, although the actual increase in the physician-per-population ratio for highdensity areas is greater than that for low-density areas.
This is in opposition to the trends discovered in previous studies. $^{2}{ }^{3}$ Furthermore, the percentage of physicians continuing their practice in high physician density areas was greater than the percentage of physicians remaining in the low-density areas. In addition, the proportion of physicians who stayed in the low-density areas tended to remain the same, but the proportion of those working in high-density and intermediate-density regions who moved to low-density areas decreased. The number of physicians across all categories (low, intermediate, high) tended to increase. With regard to migration, the absolute number of physicians moving from high to low areas is actually greater than the absolute number moving from low to high areas (for both 1996 to 2006 and 2006 to 2016).

According to Newhouse's (Harvard University) indirect competitiveness theory, increasing the number of physicians decreases regional disparity by raising the number of practitioners in rural areas. ${ }^{19}$ Also based on this theory, the greater the number of doctors per capita, the greater the rivalry between them and the more standardised the geographical distribution of doctors per capita. In addition, physicians were reported to have relocated from urban to rural areas in the USA because of economic factors. ${ }^{20}$ This study's results indicate that these patterns can also be found in Japan. The results show that rural practice is negatively associated with low physician 


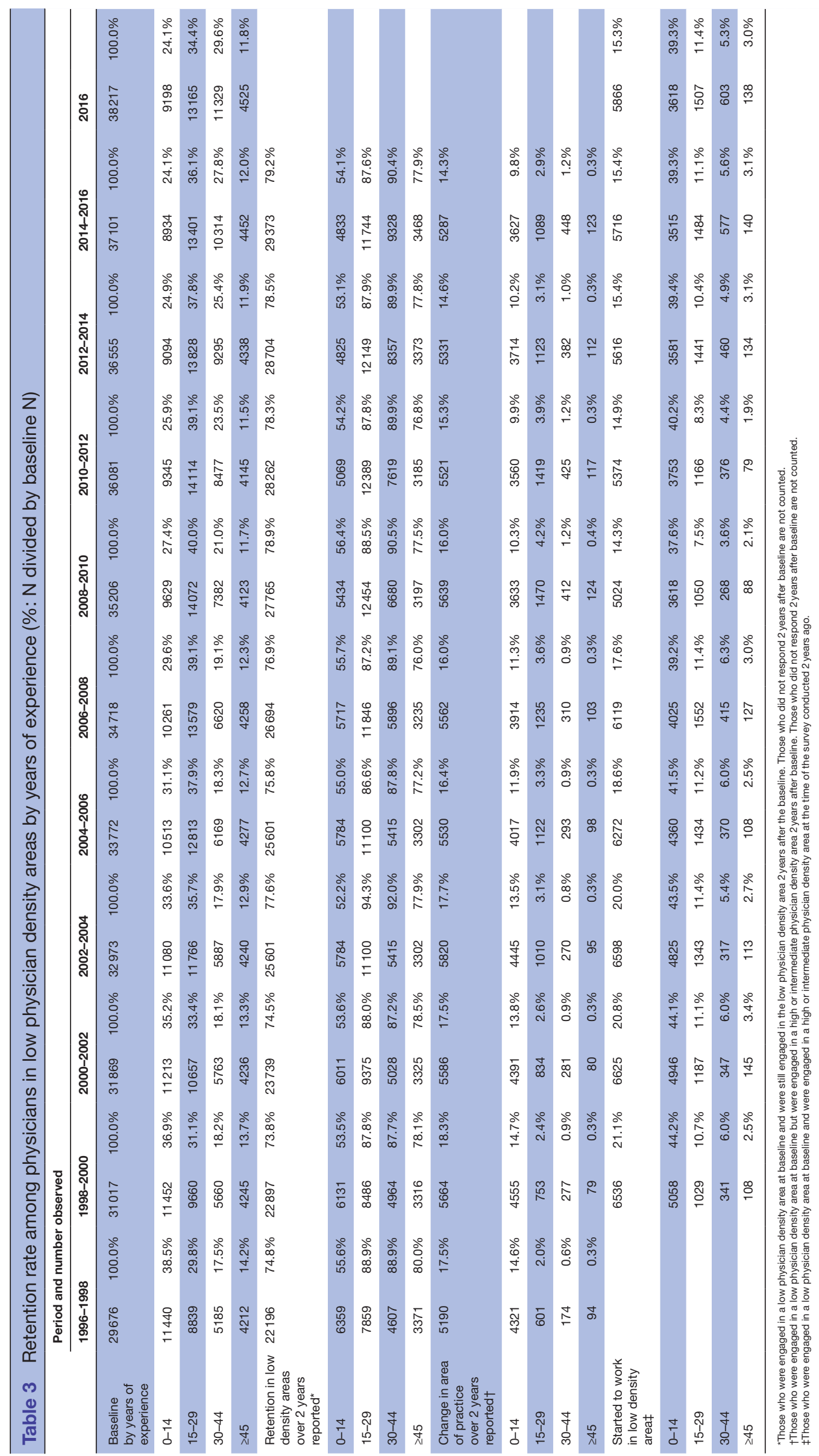


Table 4 Logistic regression analysis of physicians in high and intermediate areas and factors related to their movement to low physician density areas

\begin{tabular}{|c|c|c|c|c|c|c|c|}
\hline 1996-2006 cohort & OR & $95 \% \mathrm{Cl}$ & $P$ value & 2006-2016 cohort & OR & $95 \% \mathrm{Cl}$ & $P$ value \\
\hline Sex & & & & Sex & & & \\
\hline Male & \multicolumn{3}{|c|}{ Reference } & Male & \multicolumn{3}{|l|}{ Reference } \\
\hline Female & 0.83 & 0.78 to 0.89 & $<0.01$ & Female & 0.81 & 0.77 to 0.86 & $<0.01$ \\
\hline Age & & & & Age & & & \\
\hline$\leq 39$ & \multicolumn{3}{|c|}{ Reference } & $\leq 39$ & \multicolumn{3}{|l|}{ Reference } \\
\hline $40-54$ & 0.61 & 0.58 to 0.64 & $<0.01$ & $40-54$ & 0.63 & 0.60 to 0.66 & $<0.01$ \\
\hline $55-69$ & 0.62 & 0.57 to 0.67 & $<0.01$ & $55-69$ & 0.63 & 0.59 to 0.68 & $<0.01$ \\
\hline$\geq 70$ & 0.37 & 0.30 to 0.45 & $<0.01$ & $\geq 70$ & 0.34 & 0.28 to 0.42 & $<0.01$ \\
\hline Qualified after age 30 & & & & Qualified after age 30 & & & \\
\hline No & \multicolumn{3}{|c|}{ Reference } & No & \multicolumn{3}{|l|}{ Reference } \\
\hline Yes & 1.21 & 1.16 to 1.27 & $<0.01$ & Yes & 1.13 & 1.08 to 1.18 & $<0.01$ \\
\hline Workplace & & & & Workplace & & & \\
\hline Urban & \multicolumn{3}{|c|}{ Reference } & Urban & \multicolumn{3}{|l|}{ Reference } \\
\hline Intermediate & 0.88 & 0.85 to 0.92 & $<0.01$ & Intermediate & 0.93 & 0.89 to 0.97 & $<0.01$ \\
\hline Rural & 0.62 & 0.56 to 0.69 & $<0.01$ & Rural & 0.67 & 0.60 to 0.75 & $<0.01$ \\
\hline Physician density & & & & Physician density & & & \\
\hline High & \multicolumn{3}{|c|}{ Reference } & High & \multicolumn{3}{|l|}{ Reference } \\
\hline Intermediate & 1.19 & 1.12 to 1.25 & $<0.01$ & Intermediate & 1.34 & 1.27 to 1.41 & $<0.01$ \\
\hline Type of institution & & & & Type of institution & & & \\
\hline Clinic & \multicolumn{3}{|c|}{ Reference } & Clinic & \multicolumn{3}{|l|}{ Reference } \\
\hline University hospital & 6.15 & 5.61 to 6.74 & $<0.01$ & University hospital & 4.87 & 4.47 to 5.30 & $<0.01$ \\
\hline Other hospital & 3.89 & 3.56 to 4.24 & $<0.01$ & Other hospital & 3.37 & 3.11 to 3.64 & $<0.01$ \\
\hline Others & 4.72 & 4.16 to 5.35 & $<0.01$ & Others & 3.69 & 3.27 to 4.17 & $<0.01$ \\
\hline Specialty & & & & Specialty & & & \\
\hline Primary care & \multicolumn{3}{|c|}{ Reference } & Primary care & \multicolumn{3}{|l|}{ Reference } \\
\hline Others & 1.02 & 0.97 to 1.06 & 0.45 & Others & 1.04 & 1.00 to 1.10 & 0.05 \\
\hline
\end{tabular}

${ }^{*}$ Control variables are all based on the start of the time period.

density areas. This is related to the smaller populations in rural communities, which increases the physician-topopulation density due to the denominator rather than the numerator. This might be worth exploring further.

Moreover, initial clinical practice in university hospitals was the strongest predictor for commencing work in low physician density communities. Although a previous report found that a Japanese university's medical school had the capacity to deploy doctors to low-density community care, ${ }^{4}$ the method of physician placement at university faculties declined after the implementation of mandatory clinical training in 2004, and the geographical disparity

Table 5 The number of secondary medical areas that changed classification between the time periods

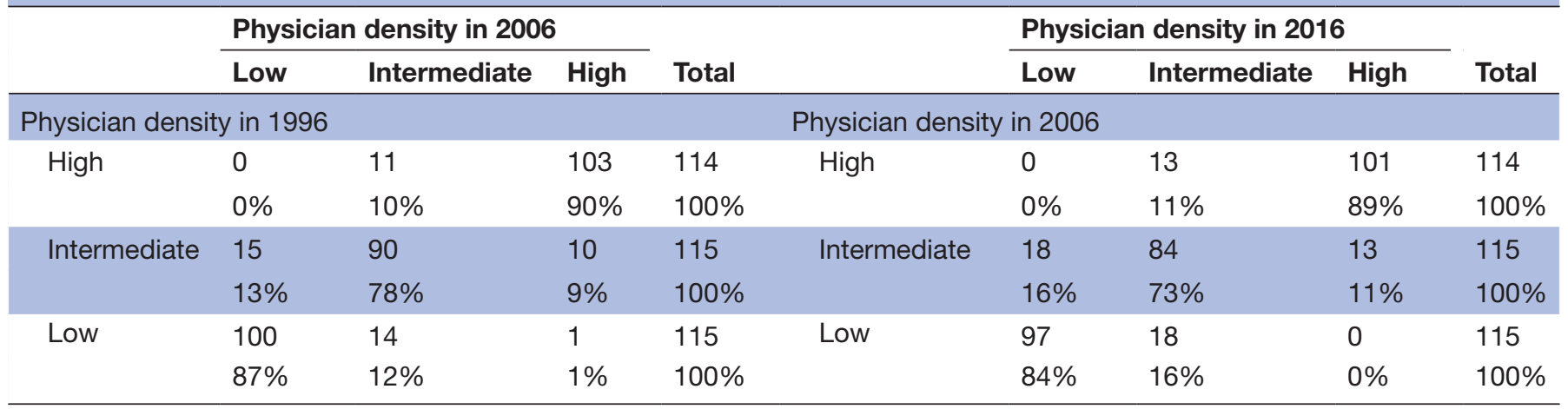


of physicians has further deteriorated.$^{5-8}$ Accordingly, in recent years, the number of doctors working in university hospitals has increased. Therefore, further review of the ways in which this process affects the potential listings of physicians is required. As the mobility of less-experienced physicians is high among all geographic categories, and the retention rate is low, especially for less-experienced physicians in low-density areas, a new system should be devised to create opportunities for younger physicians to work in low-density areas.

As I mentioned in the background section, the Medical Care Act revision draft took effective measures for geographical maldistribution. It requires hospital directors to procure those with work experience in low physician density areas for a certain period. ${ }^{11}$ This study's results would support this policy's effects.

There are some limitations to this report. First, the workplace was self-reported, which may have resulted in misclassifications. Second, this analysis only focused on correlations and was unable to determine causality. Future studies could use interviews and questionnaires to facilitate more comprehensive research. Third, I divided the SMAs into three groups according to population density, but changes in classification may cause variation in the results. Fourth, the observation period was 20 years. The effects of various environmental changes, such as the global economic crisis, policy changes for physician maldistribution, and population ageing, were not considered. Fifth, the 'other' physician category includes public health centres, industrial physicians and unemployed physicians. A heterogenous category may affect the results. Sixth, tables 2 and 4 analyse the whereabouts of physicians at two points, 1996 and 2006, or 2006 and 2016, and do not consider changes during the period.

Contributors The author is solely responsible for all aspects of the study.

Funding The author has not declared a specific grant for this research from any funding agency in the public, commercial or not-for-profit sectors.

Competing interests None declared.

Patient and public involvement Patients and/or the public were not involved in the design, or conduct, or reporting, or dissemination plans of this research.

Patient consent for publication Not required.

Ethics approval I received the MHLW's approval to use the data set, and this research was approved by the Harvard T.H. Chan School of Public Health institutional review board (№. 18-1422). The requirement for informed consent was waived by the review board as the original surveys were mandatory.

Provenance and peer review Not commissioned; externally peer reviewed. Data availability statement № data are available.

Open access This is an open access article distributed in accordance with the Creative Commons Attribution Non Commercial (CC BY-NC 4.0) license, which permits others to distribute, remix, adapt, build upon this work non-commercially, and license their derivative works on different terms, provided the original work is properly cited, appropriate credit is given, any changes made indicated, and the use is non-commercial. See: http://creativecommons.org/licenses/by-nc/4.0/.

ORCID iD

Masatoshi Ishikawa http://orcid.org/0000-0001-9855-3233

\section{REFERENCES}

1 Matsumoto M, Inoue K, Kajii E, et al. Retention of physicians in rural Japan: concerted efforts of the government, prefectures, municipalities and medical schools. Rural Remote Health 2010;10:1432.

2 Kobayashi Y, Takaki H. Geographic distribution of physicians in Japan. Lancet 1992;340:1391-3.

3 Matsumoto M, Inoue K, Bowman R, et al. Geographical distributions of physicians in Japan and US: impact of healthcare system on physician dispersal pattern. Health Policy 2010;96:255-61.

4 Inoue K, Matsumoto M. Japan's new postgraduate medical training system. Clin Teach 2004;1:38-40.

5 Toyabe S-I. Trend in geographic distribution of physicians in Japan. Int J Equity Health 2009;8:5.

6 Tanihara S, Kobayashi Y, Une H, et al. Urbanization and physician maldistribution: a longitudinal study in Japan. BMC Health Serv Res 2011;11:260.

7 Hara K, Otsubo T, Kunisawa S, et al. Examining sufficiency and equity in the geographic distribution of physicians in Japan: a longitudinal study. BMJ Open 2017;7:e013922.

8 Matsumoto M, Kimura K, Inoue K, et al. Aging of hospital physicians in rural Japan: a longitudinal study based on national census data. PLoS One 2018;13:e0198317.

9 Committee on Demand and Supply of Health Workers. Second interim report of Subcommittee on physicians. Tokyo: Ministry of Health, Labour and Welfare, 2017.

10 World Health Organization. Increasing access to health workers in remote and rural areas through improved retention. Geneva: WHO, 2010.

11 Committee on Demand and Supply of Health Workers. Fourth interim report of Subcommittee on physicians. Tokyo: Ministry of Health, Labour and Welfare, 2019.

12 Inoue K, Matsumoto M, Toyokawa S, et al. Transition of physician distribution (1980-2002) in Japan and factors predicting future rural practice. Rural Remote Health 2009;9:1070.

13 Vanasse A, Ricketts TC, Courteau J, et al. Long term regional migration patterns of physicians over the course of their active practice careers. Rural Remote Health 2007;7:812.

14 Xierali IM, Nivet MA, Rayburn WF. Relocation of ObstetricianGynecologists in the United States, 2005-2015. Obstet Gynecol 2017;129:543-50.

15 Shimada N, Kondo T. Ishi-Shikaishi-Yakuzaishi chosa no kohyo data wo shiyou shita todokede ritsu no suikei [estimation of actual report rates using data from the survey of physicians, dentists, and pharmacists]. Nihon Koshu Eisei Zasshi [Jpn J Public Health] 2004;51:117-32.

16 Ricketts TC, Johnson-Webb KD, Randolph RK. Populations and places in rural America. In: Ricketts TC, ed. Rural health in the United States. New York: Oxford University Press, 1999: 7-24.

17 Ministry of Health, Labour and Welfare. Second interim report of Subcommittee on physicians. Tokyo: Ministry of Health, Labour and Welfare, 2017. https://www.mhlw.go.jp/stf/shingi2/0000188999.html

18 Matsumoto M, Inoue K, Kajii E. A contract-based training system for rural physicians: follow-up of Jichi medical university graduates (1978-2006). J Rural Health 2008;24:360-8.

19 Newhouse JP. Geographic access to physician services. Annu Rev Public Health 1990;11:207-30.

20 Ricketts TC, Randolph R. Urban-Rural flows of physicians. J Rural Health 2007;23:277-85. 